\title{
TWO NEW GENERA OF HYDROPTILIDAE FROM THE NEOTROPICS (TRICHOPTERA: HYDROPTILIDAE: STACTOBIINI)
}

\author{
Steven C. Harris, ${ }^{1}$ Oliver S. Flint, JR. ${ }^{2}$ and Ralph W. Holzenthal ${ }^{3}$ \\ ${ }^{1}$ Department of Biology, Clarion University, Clarion, Pennsylvania 16214, U.S.A. \\ (E-mail: harris@ @larion.edu); \\ ${ }^{2}$ Department of Entomology, National Museum of Natural History, Smithsonian \\ Institution, Washington, DC 20560, U.S.A. (E-mail: flint.oliver@nmnh.si.edu); and \\ ${ }^{3}$ Department of Entomology, University of Minnesota, 1980 Folwell Ave, 219 \\ Hodson Hall, St. Paul, MN 55108, U.S.A. (E-mail: holze001@umn.edu)
}

\begin{abstract}
Two new monotypic genera of stactobine microcaddisflies (Trichoptera: Hydroptilidae), Orinocotrichia, and Tizatetrichia, are described and illustrated from Venezuela and Costa Rica, respectively. Keys are provided for males and females of the New World genera comprising the tribe Stactobiini.
\end{abstract}

Key words: Trichoptera, Hydroptilidae, microcaddisflies, new genera, Neotropics, Venezuela, Costa Rica, key

The family Hydroptilidae has undergone several attempts at subfamily classification beginning with Neilsen (1948), who proposed the subfamilies Orthotrichiinae, for the genera Orthotrichia and Ithytrichia, and Hydroptilinae, for Agraylea, Oxyethira and Hydroptila. Botosaneanu (1956) modified this scheme in erecting the subfamily Stactobiinae for the genus Stactobia and several other related genera, which although not listed probably included Plecthrotrichia, Plethus, and Stactobiella. Flint (1970) basically followed the plan of Botosaneanu (1956), adding the subfamily Leucotrichinae, for the genus Leucotrichia and a number of related genera. More recently, Marshall (1979) modified the classification first proposed by Ross (1956) and recognized only two subfamilies, the Ptilocolepinae and Hydroptilinae, but divided the latter subfamily into six tribes, the Stactobiini, Leucotrichiini, Orthotrichiini, Ochrotrichiini, Hydroptilini, and Neotrichiini, which largely corresponds to the subfamily classification proposed by Flint (1970). This is the classification scheme adopted by Wells (1990) in her treatment of the Stactobiini of New Guinea and by Wiggins (1996) in his book dealing with the caddisfly larvae of North America, and is the format we follow in this paper.

Stactobiini as presently defined contains 10 genera and some 300 species, most of which occur in the Old World, where they are especially diverse in Africa, the Indian subcontinent, southeast Asia, and New Guinea. In the New World, there are only three genera presently known: Stactobiella in North America, and Bredinia and Flintiella in Central and South America (Flint et al., 1999). As a tribe, the Stactobiini are difficult to separate from the Leucotrichiini, and both are thought to be early offshoots from the Hydroptilinae (Marshall, 1979). Adults of Stactobiini can be distinguished from Leucotrichiini on the basis of the following characteristics: metascutellum narrow and rectanguloid, nearly as wide as scutum; abdominal segment 
VIII annular and complete dorsally; abdominal segment IX usually with elongate anterior apodemes; and phallus tubular, lacking a median constriction and associated structures. The larvae of both Stactobiini and Leucotrichiini are problematical, owing to a lack of larval associations in many genera and considerable variation within a genus as a result of adaptations to specific, often madicolous, habitats. With the recent discoveries of new genera and species in both the Leucotrichiini and the Stactobiini, the tribal limits of these two groups have become increasingly problematical. Until we can complete a comprehensive revision of all genera comprising both tribes, we prefer to let the current classification stand.

In this paper, we begin our review of the Stactobiini of the Neotropics by describing two new genera, one from Costa Rica and another from Venezuela. Types of species described in this paper are deposited in the collections of the National Museum of Natural History, Smithsonian Institution, Washington, D.C. Terminology follows that of Marshall (1979). Length is measured from the tip of the head to the end of the wings and is given as a range with a series of specimens.

Orinocotrichia, new genus

Figs. 1-3

Type species. Orinocotrichia calcariga, new species.

Diagnosis. Adult. Coloration, brown in alcohol. Head without ocelli, pair of posterolateral warts; tentorium with anterior arms complete, apparently unconnected mesally (Fig. 1A). Antennae with 18 segments, unmodified, shorter than forewing. Pronotum narrow with pair of mesal warts; mesoscutellum with transverse suture; metascutellum transversely rectangular, posterior and anterior margins nearly parallel (Fig. 1A). Spur formula of legs 0, 2, 3, outer spurs about half length of inner spurs (Fig. 1B). Wings narrow, accuminate; venation reduced with only short, basal anterior and posterior veins in fore and hind wings (Fig. 1C).

Male genitalia (Fig. 2). Abdominal segment VII without sternal process. Segment IX with elongate anterolateral apodemes; posterolateral margin developed as narrow, pointed process, sternite reduced. Segment X lobate. Inferior appendages short, lacking an elongate seta. Subgenital plate a narrow shelf. Phallus tubular with apicolateral sclerites which are reflexed apicad, with mesal ejaculatory duct.

Female genitalia (Fig. 3). Oviscapt type, abdominal segment VIII with elongate apodemes from posterior and lateral margins. Segment IX with lateral apodemes. Bursa copulatrix oval and membranous, keyhole-like opening near base of vaginal sclerite.

Larva. Uknown.

Discussion. Orinocotrichia is most closely related to Flintiella based on the elongate apodemes from the anterior of abdominal segment IX, the loss of ocelli, and the triangular warts along the posterior of the head. The "keyhole" structure of the vaginal sclerite of the bursa copulatrix is also similar to that seen in Flintiella (Fig. 4), although in Orinocotrichia this sclerite is posterior as opposed to anterior in position. The new genus is also separated based on the reduced inferior appendages and simple, unmodified subgenital plate in the male. Orinocotrichia is represented by a single species from the Río Cataniapo in Venezuela. 


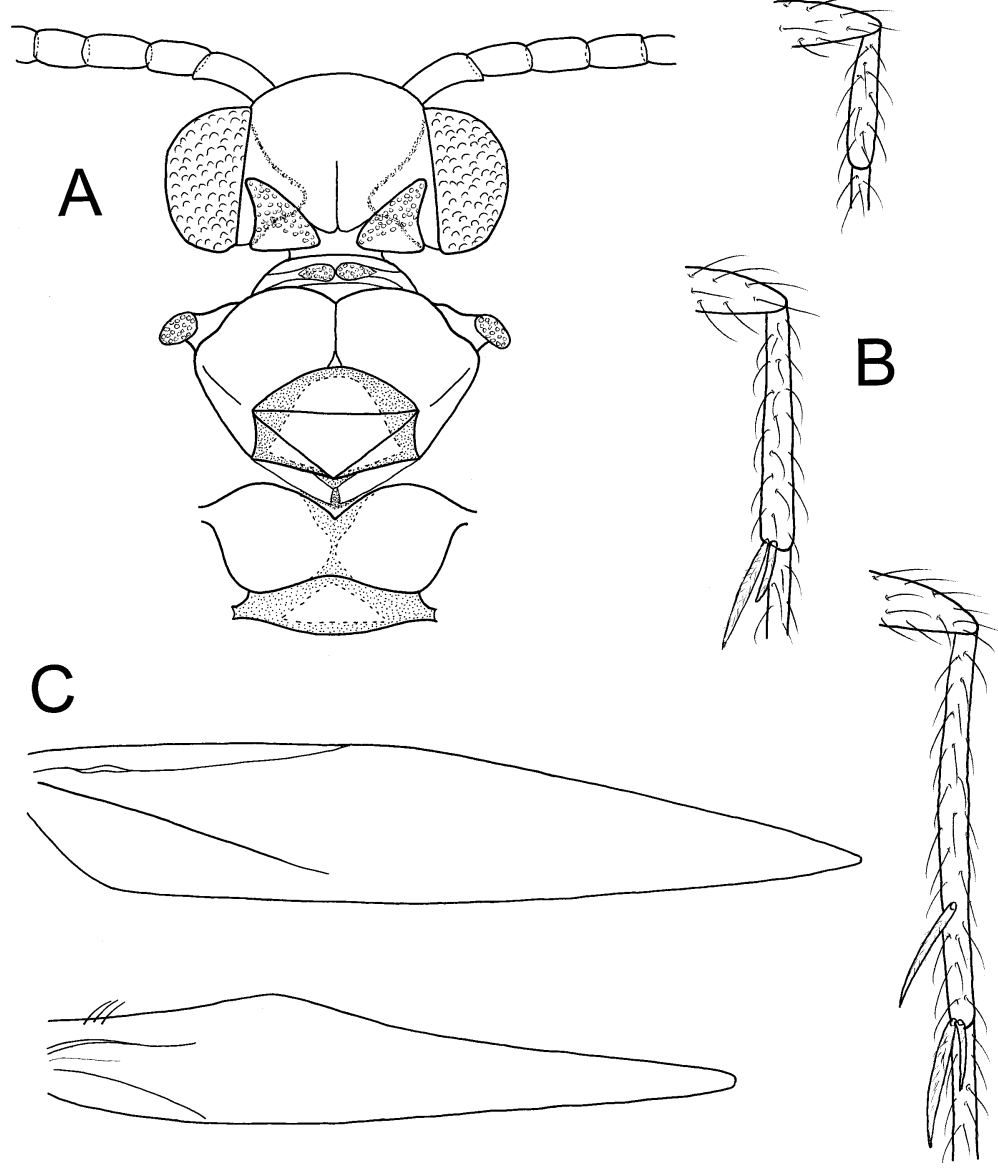

Fig. 1. Orinocotrichia calcariga, new species. A. Head and thorax, dorsal view. B. Fore, mid and hind leg. C. Fore and hind wing.

Etymology. The generic name is derived from the Río Orinoco basin, of which the Río Cataniapo is a part.

Orinocotrichia calcariga, new species

Figs. 1-3

Description. Male. Length $1.8 \mathrm{~mm}$. Antennae with 18 segments. Brown in alcohol. Genitalia as in Fig. 2. Abdominal segments VII and VIII annular. Segment IX reduced to narrow bridge ventrally, elongate apodemes originating from anterolateral margins, extending into segment VI; posterolateral margin produced as thin, elongate process; in dorsal view this process extends out from body, narrowing distally; in ventral view these processes dorsad of large lateral lobes. Segment X a truncate lobe 


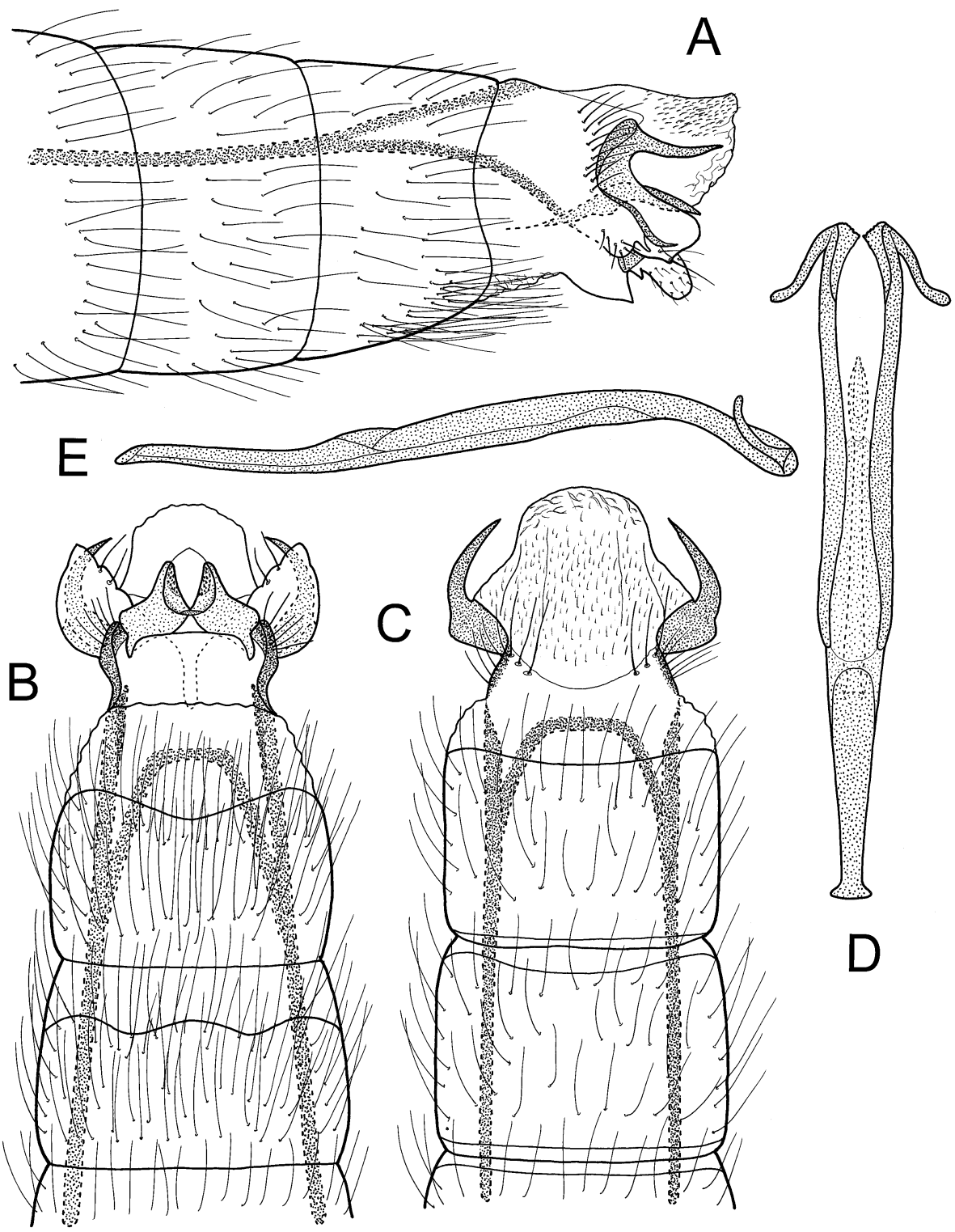

Fig. 2. Orinocotrichia calcariga, new species, male genitalia. A. Lateral. B. Ventral. C. Dorsal. D. Phallus, dorsal. E. Phallus, lateral

Fig. 3. Orinocotrichia calcariga, new species, female genitalia. A. Terminal abdominal segments, ventral. B. Bursa copulatrix, ventral. 


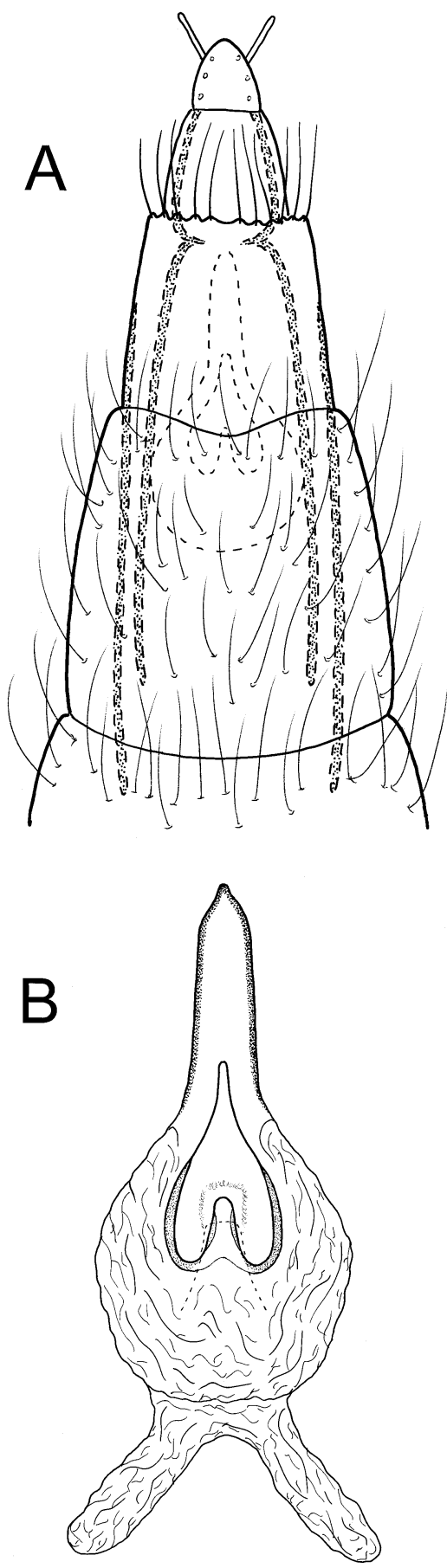



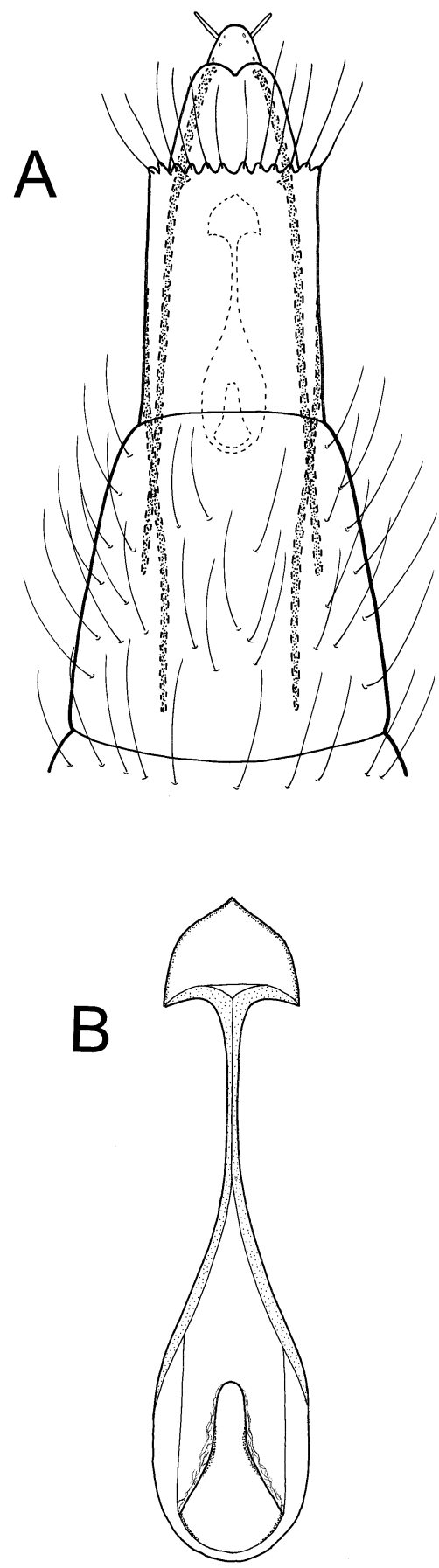
in lateral view, dorsally lobate, rounded apically. Inferior appendages short and rounded apically in lateral view; in ventral view triangular, fused subbasally, excavated on mesal margins. Subgenital plate a narrow shelf in lateral view. Phallus tubular, with apicolateral sclerites, recurved at apex, ejaculatory duct mesad and elongate.

Female. Length 1.8-2.3 mm. Antennae with 17 segments. Color and features of the head and thorax as in male. Genitalia as in Fig. 3. Abdominal segment VII elongate. Segment VIII rectangular, with ring of setae on posterior margin, pair of elongate mesal apodemes extending into segment VI, second pair of elongate apodemes originating at anterolateral margins, extending into segment VI. Segment IX short and square with pair of lateral apodemes connecting anteriorly with mesal apodemes of VIII. Segment X short, rounded distally, bearing pair of lateral papillae. Bursa copulatrix membranous and round, pair of membranous lobes posteriorly, anteriorly narrowing to thin process; vaginal sclerite with keyhole-like opening posteriorly, band of sclerotization laterally.

Types. Holotype, ô: VENEZUELA, T. F. Amazonas, Río Cataniapo, $10 \mathrm{~km} \mathrm{~S}$ Puerto Ayacucho, III-9-1984, O. Flint (NMNH). Paratypes: VENEZUELA, T. F. Amazonas, same data as holotype, 5 ㅇ (NMNH).

Etymology. The species name is derived from the Latin "spur."

Tizatetrichia, new genus

Figs. 5, 6

Type species. Tizatetrichia costaricensis, new species.

Diagnosis. Adult. Coloration, brown in alcohol. Head with 3 ocelli, pair of posterolateral warts; tentorium with anterior arms complete, apparently unconnected mesally (Fig. 5A). Antennae with 18 segments, unmodified. Pronotum narrow, with pair of mesal and lateral warts; mesoscutellum with transverse suture; metascutellum transversely rectangular, posterior and anterior margins nearly parallel (Fig. 5A). Spur formula of legs 0,2 , 4; outer spurs about half length of inner spurs (Fig. 5B). Wings narrow, acuminate; venation reduced with only short, basal anterior and posterior veins in fore and hind wings (Fig. 5C).

Male genitalia (Fig. 6). Abdominal segment VII annular, lacking posteromesal process from venter. Segment VIII annular with short, anterolateral apodemes. Segment IX without anterolateral apodemes, reduced laterally to narrow bridge. Segment $\mathrm{X}$ a membranous lobe dorsally, posterolateral margin produced to slender process bearing apical spines. Inferior appendages very long, gradually tapering distally. Subgenital plate present, divided into lateral, acute processes. Phallus tubular, deeply divided apically, each branch with mesal sclerite basally.

Female and larva. Unknown.

Fig. 4. Flintiella, undescribed species from Mexico, female genitalia. A. Terminal abdominal segments, ventral. B. Bursa copulatrix, ventral. 


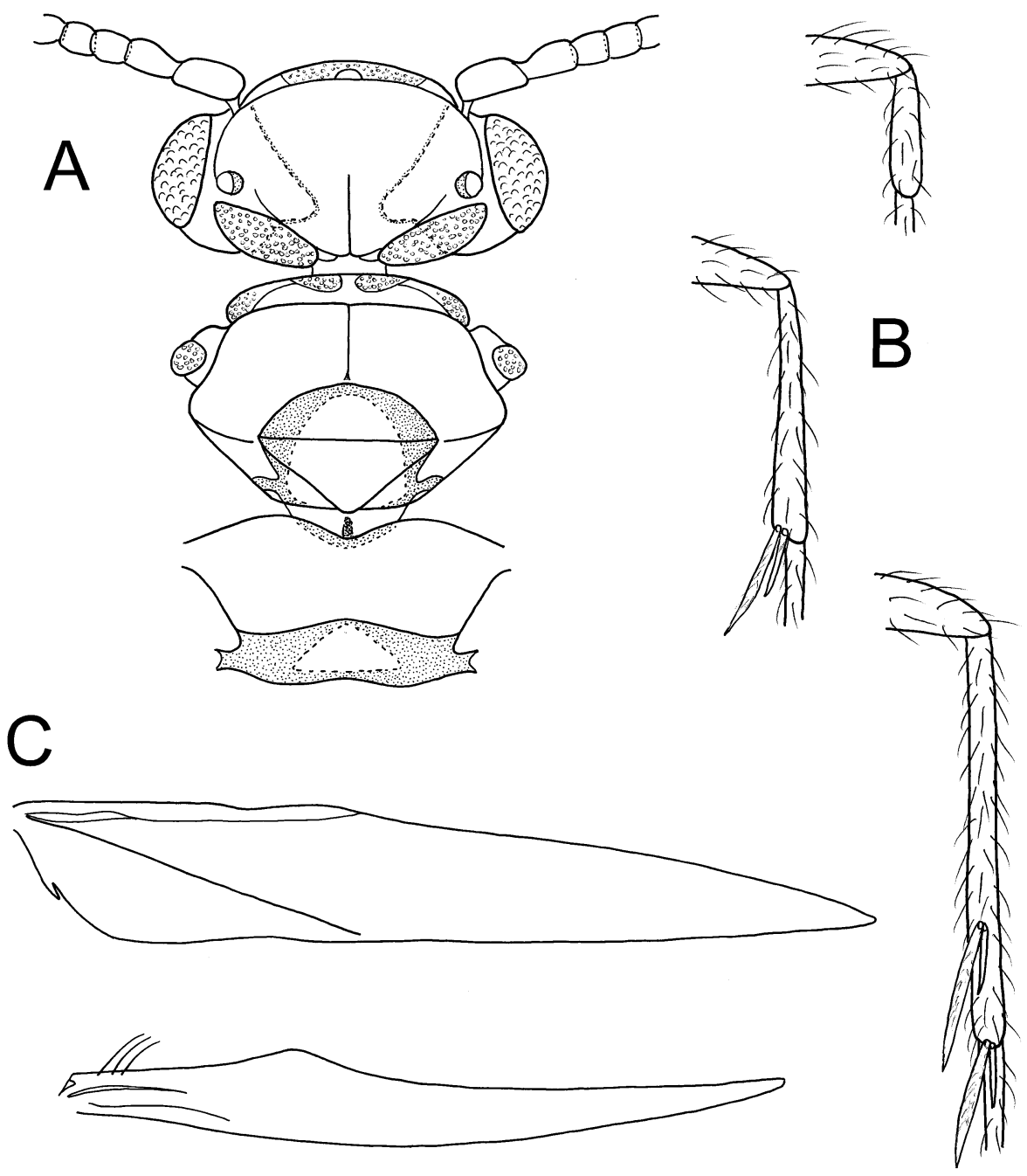

Fig. 5. Tizatetrichia costaricensis, new species. A. Head and thorax, dorsal view. B. Fore, mid, and hind leg. C. Fore and hind wing.

Discussion. Tizatetrichia is most closely related to Bredinia based on the shared feature of lateral apodemes from the posterior margin of abdominal segment IX. The new genus is separated from Bredinia on the basis of three apomorphies: venter of segment $\mathrm{X}$ well developed and bearing heavy spines; subgenital plate reduced to narrow bands; and inferior appendages extremely long and thin. Tizatetrichia is represented by a single species from the Río Tizate in northwestern Costa Rica. Etymology. The generic name is derived from the type locality, the Río Tizate. 


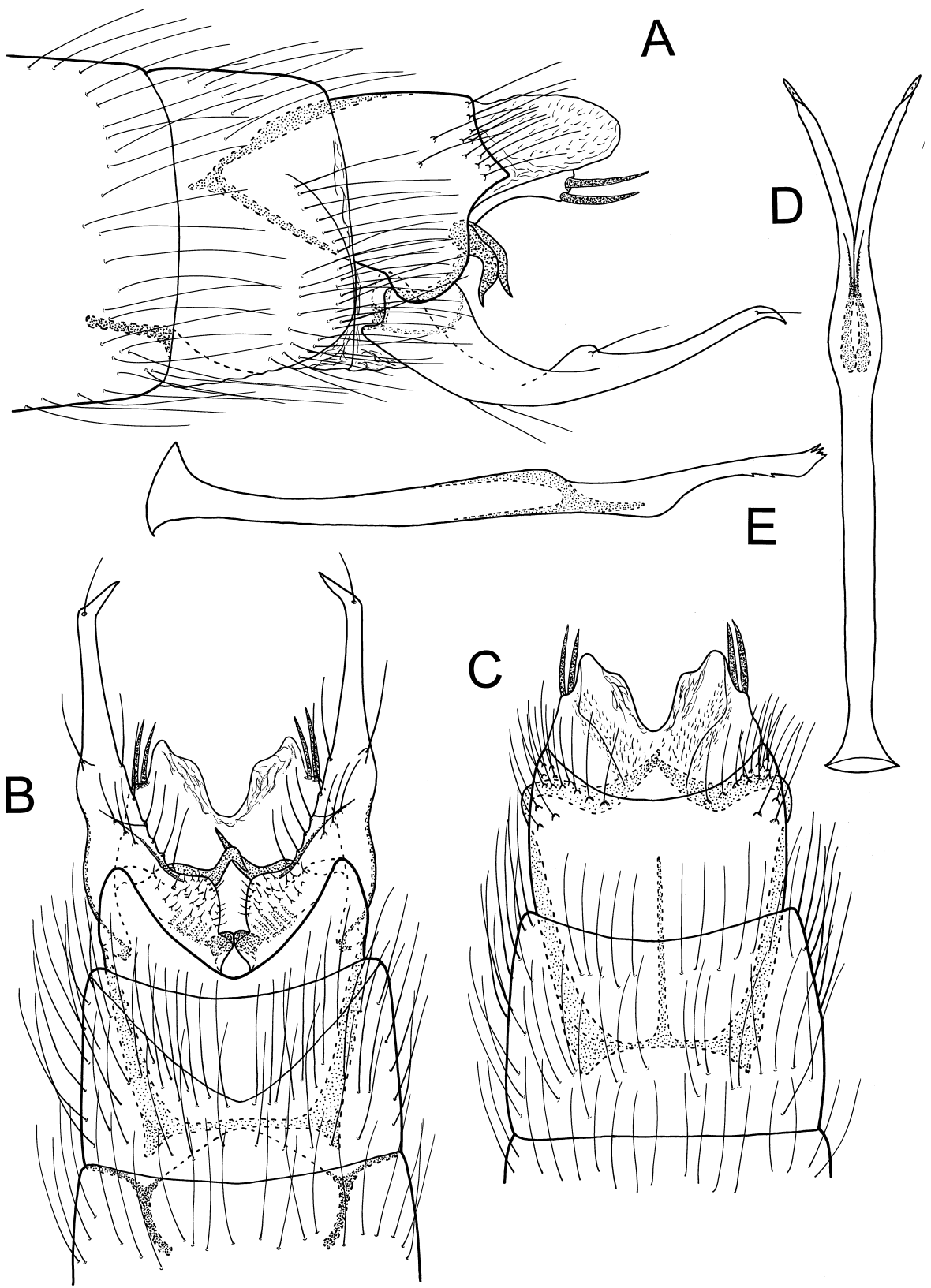

Fig. 6. Tizatetrichia costaricensis, new species, male genitalia. A. lateral. B. Ventral. C. Dorsal. D. Phallus, dorsal. E. Phallus, lateral. 
Tizatetrichia costaricensis, new species

Figs. 5, 6

Description. Male. Length $1.6 \mathrm{~mm}$. Antennae with 18 segments. Brown in alcohol. Genitalia as in Fig. 6. Abdominal segment VIII annular; short, anterolateral apodemes. Segment IX reduced to narrow bridge ventrally; emarginate on posterior margin in dorsal and ventral views. Segment X a membranous lobe dorsally, venter developed into rectangular process bearing pair of heavy spines; in dorsal view, deeply emarginate posteriorly, membranous mesally, laterally bearing pair of heavy spines. Inferior appendages elongate, wide basally, tapering distally and curving upward, seta apically and at mid-length; in ventral view elongate tapering distally, apices acute and angled inward. Subgenital plate in lateral view divided into narrow, acute processes which curve ventrally; in ventral view appearing as pair of lateral rods which project mesally. Phallus tubular, deeply divided at apex, each lateral branch with mesal sclerite at base.

Female. Unknown.

Types. Holotype, $₫$ : COSTA RICA, Guanacaste, Río Tizate, $7.2 \mathrm{~km}$ NE Cañas Dulces, $10.773^{\circ} \mathrm{N}, 85.449^{\circ} \mathrm{W}$, el. 275 m, VI-28-1986, Holzenthal, Heyn, Armitage (NMNH).

Etymology. The species is named for the country of Costa Rica.

\section{KEY TO THE NEW WORLD STACTOBIINI GENERA}

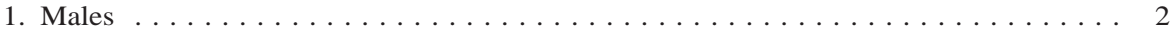

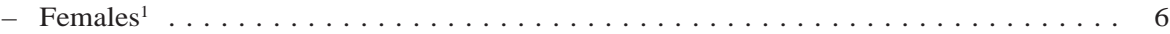

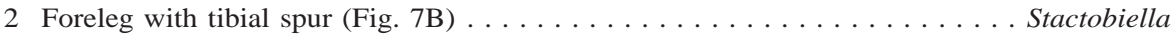

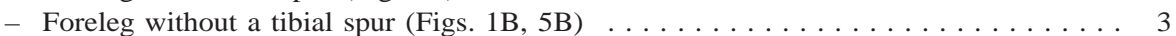

3 Ocelli present (Figs. 5A, 8A); leg spurs 0, 2, 4 (Figs. 5B, 8B) $\ldots \ldots \ldots \ldots \ldots$

- Ocelli absent (Figs. 1A, 10A); leg spurs 0, 2, 3 (Figs. 1B, 10B) . . . . . . . . . 5

4 Inferior appendages with elongate, heavy seta from posterolateral margin (Fig. 9B); anterolateral margin of segment IX produced into apodemes (Fig. 9A) . . . . . Bredinia

- Inferior appendages without elongate, heavy seta from posterolateral margin (Fig. 6B); anterolateral margin of segment IX not produced into apodemes (Fig. 6A) . . . . . . $\ldots \ldots \ldots \ldots \ldots \ldots \ldots \ldots \ldots \ldots \ldots \ldots \ldots \ldots \ldots \ldots \ldots \ldots \ldots \ldots$ Tizatetrichia

5 Inferior appendages prominent and usually elongate (Figs. 11A, 11B); subgenital plate elongate and divided into several processes (Fig. 11A); phallus tubular and simple (Fig.

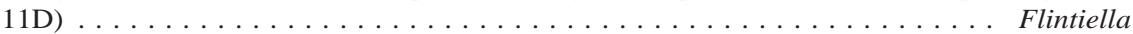

- Inferior appendages short (Fig. 2A, 2B); subgenital plate simple (Fig. 2A); phallus heavily sclerotized, with pair of lateral processes (Fig. 2D) . . . . . . Orinocotrichia

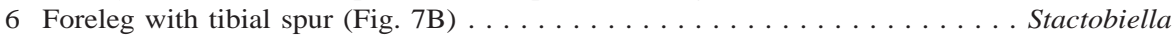

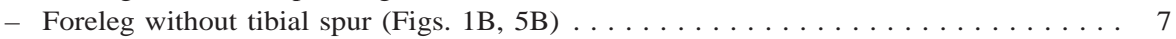

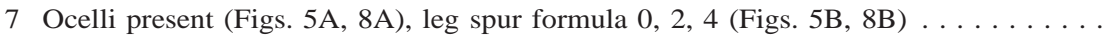
$\ldots \ldots \ldots \ldots \ldots \ldots \ldots \ldots \ldots \ldots \ldots \ldots \ldots \ldots \ldots \ldots \ldots \ldots \ldots$ Tizatetrichia

- Ocelli absent (Figs. 1A, 10A), leg spur formula 0, 2, 3 (Figs. 1B, 10B) . . . . . . . 8

8 Bursa copulatrix with vaginal sclerite central and with posteromesal process (Fig. 3) $\ldots \ldots \ldots \ldots \ldots \ldots \ldots \ldots \ldots$ Orinocotrichia

- Bursa copulatrix with vaginal sclerite anterior and without posteromesal process (Fig.

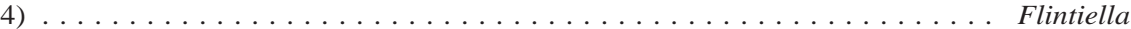

${ }^{1}$ The female of Tizatetrichia is unknown 

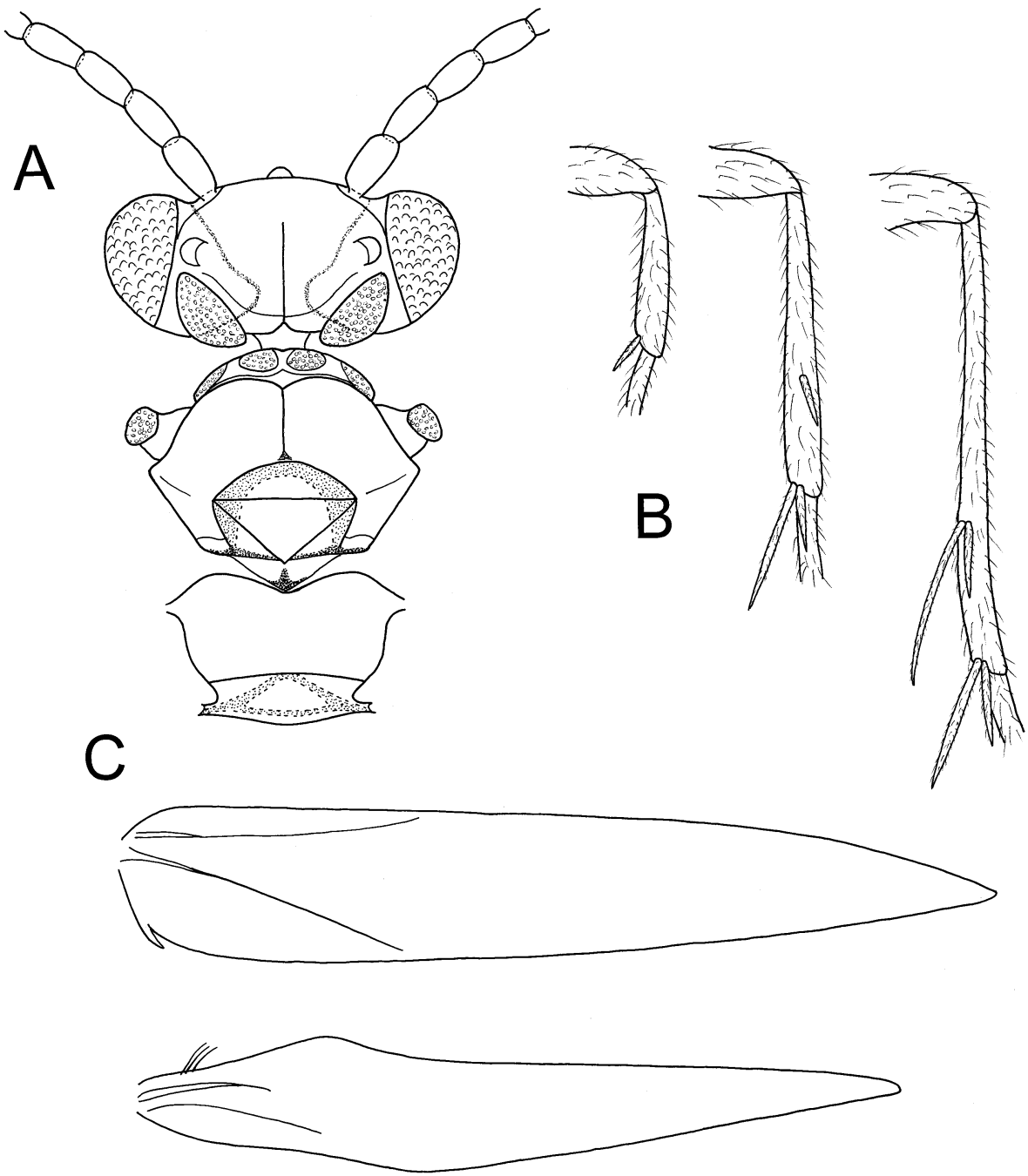

Fig. 7. Stactobiella delira (Ross). A. Head and thorax, dorsal view. B. Fore, mid, and hind leg. C. Fore and hind wing. 


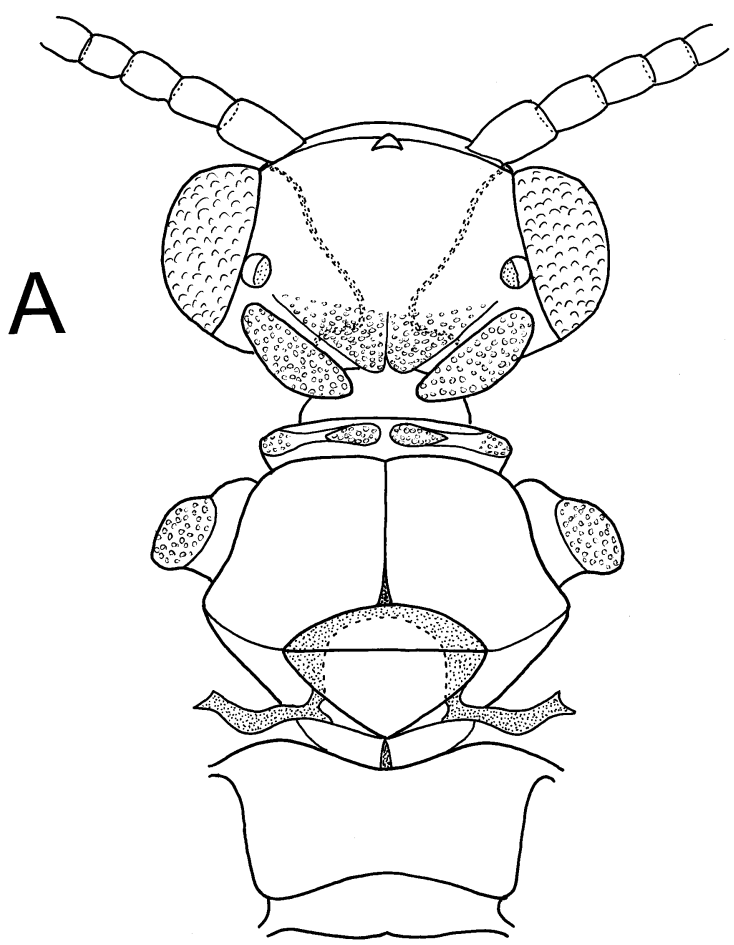

C
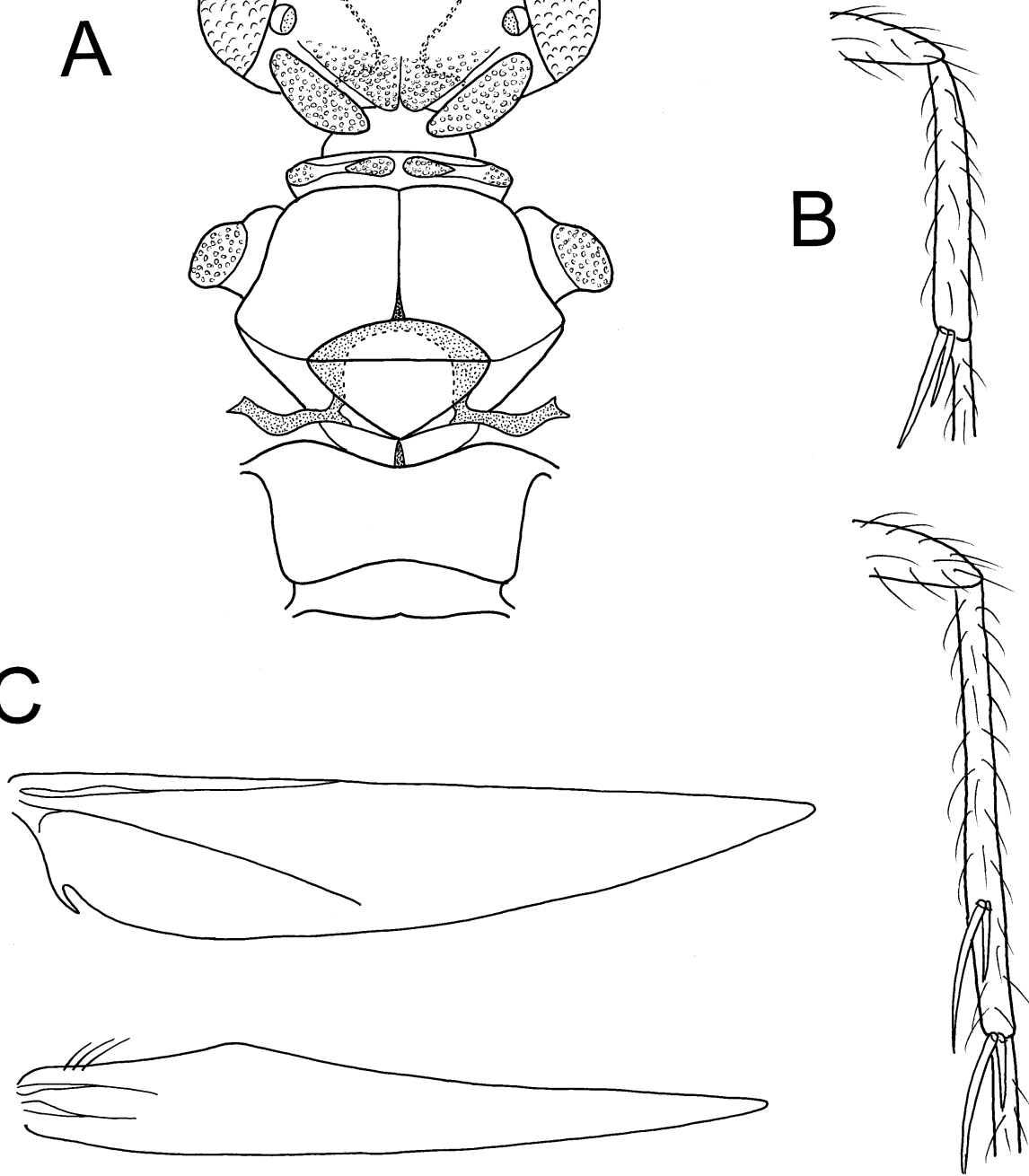

Fig. 8. Bredinia costaricensis (Flint). A. Head and thorax, dorsal view. B. Fore, mid, and hind leg. C. Fore and hind wing. 


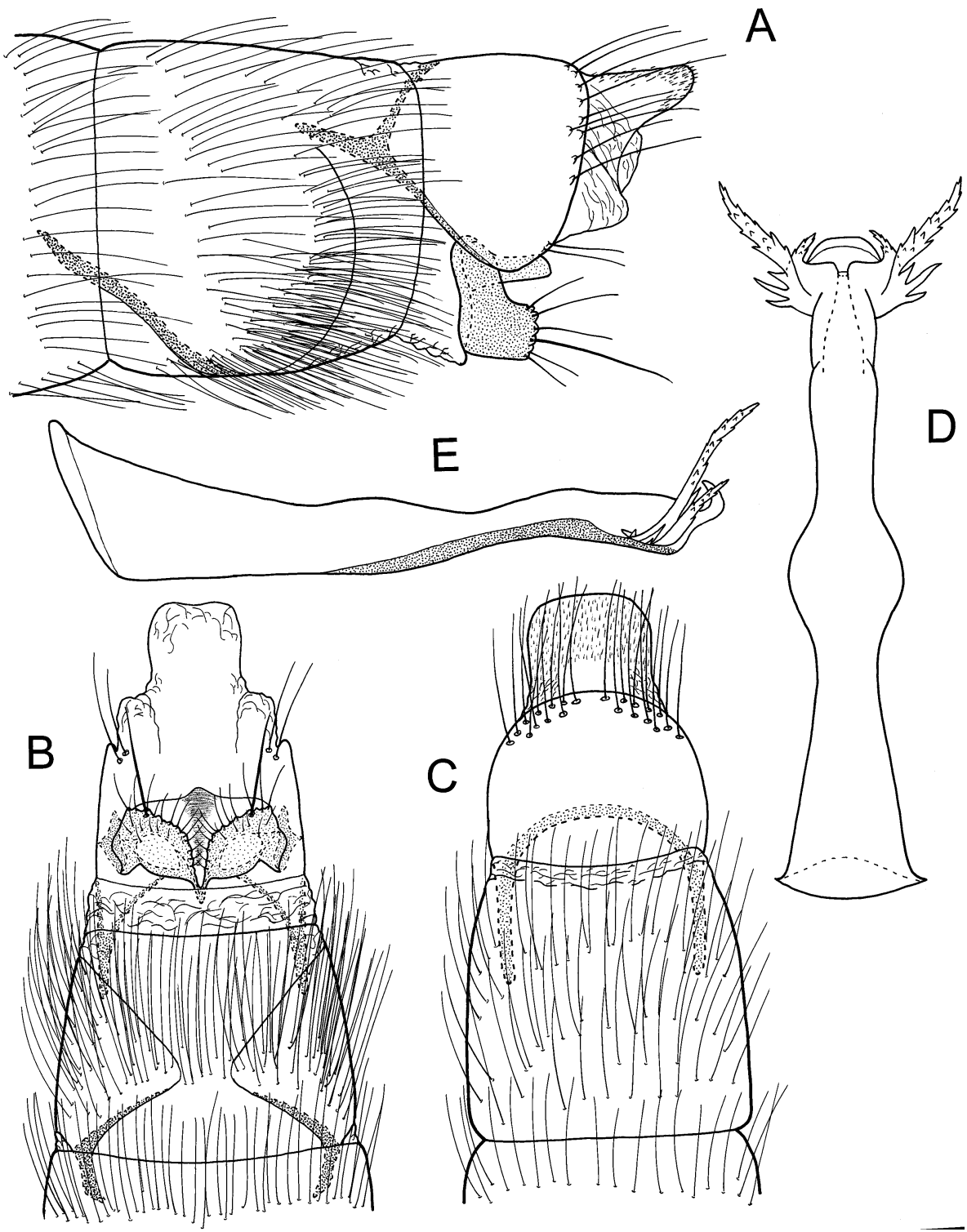

Fig. 9. Bredinia costaricensis (Flint), male genitalia. A. Lateral. B. Ventral. C. Dorsal. D. Phallus, dorsal. E. Phallus, lateral. 


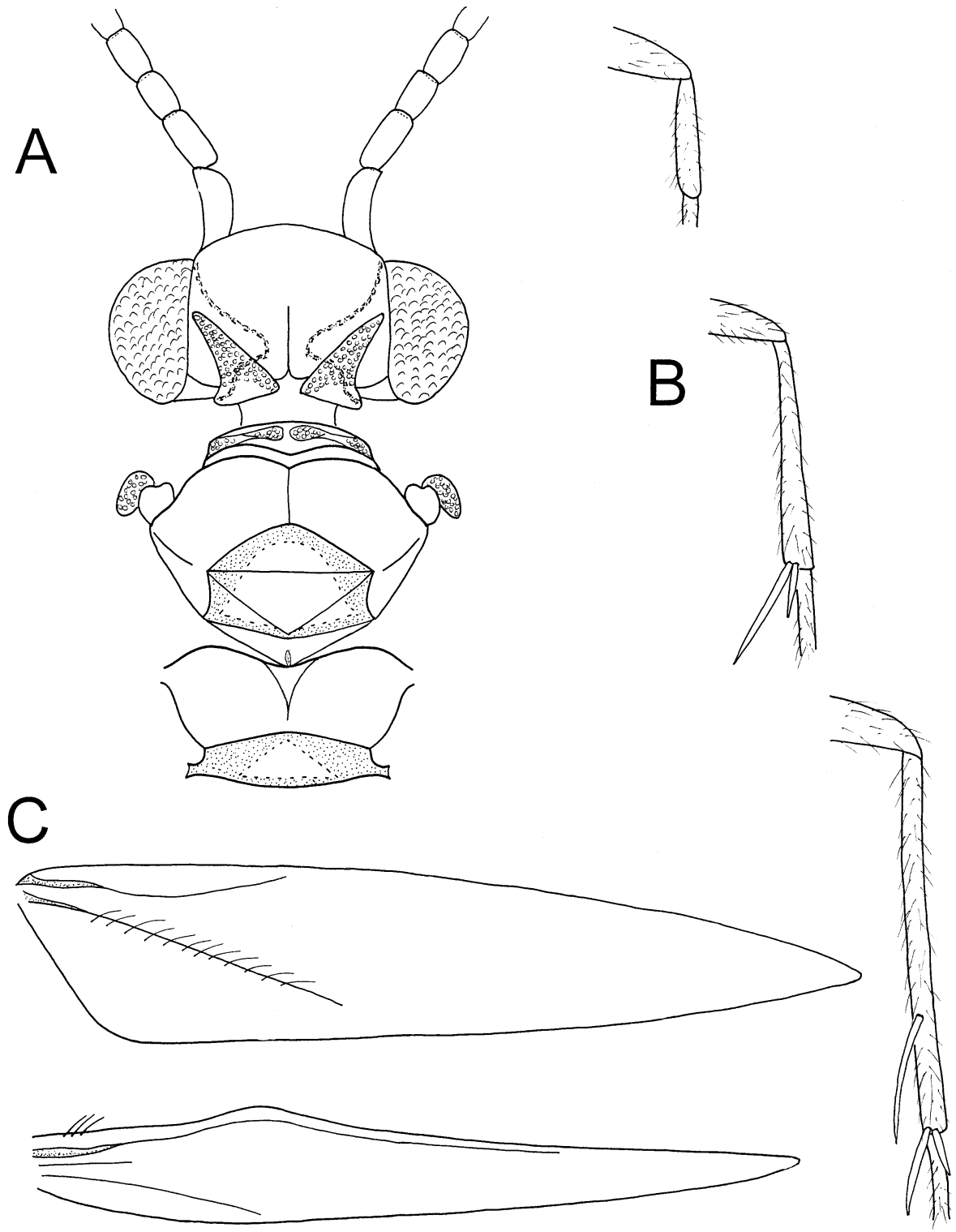

Fig. 10. Flintiella, undescribed species from Costa Rica. A. Head and thorax, dorsal view. B. Fore, mid, and hind leg. C. Fore and hind wing.

Fig. 11. Flintiella, undescribed species from Costa Rica, male genitalia. A. Lateral. B. Ventral. C. Dorsal. D. Phallus, dorsal. E. Phallus, lateral. 


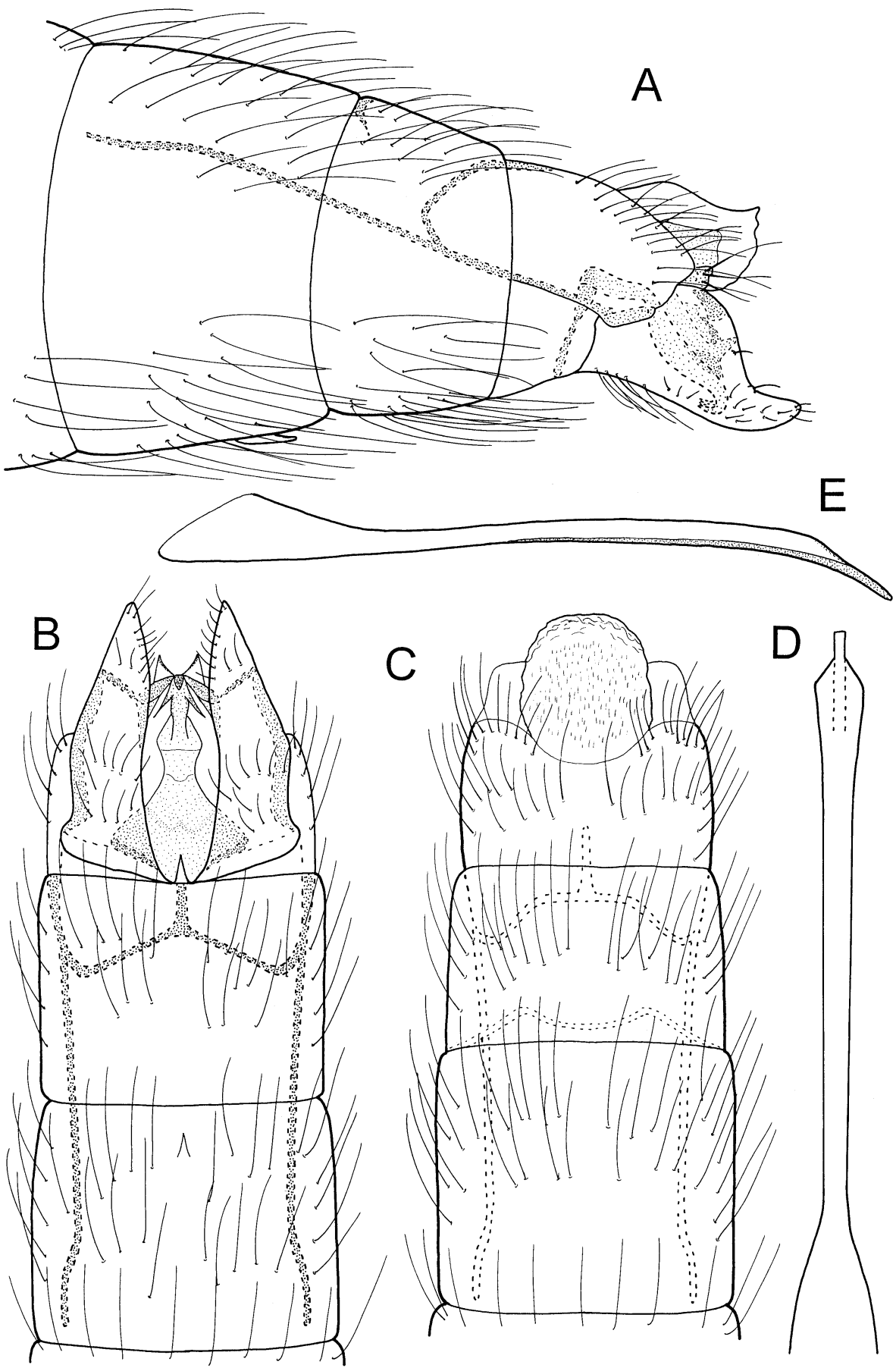




\section{ACKNOWLEDGMENTS}

Fieldwork in Costa Rica by Holzenthal was supported by National Science Foundation grant BSR-8512368. Subsequent systematics research by Holzenthal and Harris was supported by NSF grant DEB-9400632.

\section{LITERATURE CITED}

Flint, O. S., Jr. 1970. Studies of Neotropical caddisflies, X: Leucotrichia and related genera from North and Central America (Trichoptera: Hydroptilidae). Smithsonian Contributions to Zoology 60:1-64.

Flint, O. S., Jr., R. W. Holzenthal and S. C. Harris. 1999. Catalog of the Neotropical caddisflies (Insecta: Trichoptera). Ohio Biological Survey, Columbus, Ohio, 239 pp.

Marshall, J. E. 1979. A review of the genera of the Hydroptilidae (Trichoptera). Bulletin of the British Museum of Natural History (Entomology) 39:135-239.

Neilsen, A. 1948. Postembryonic development and biology of the Hydroptilidae (Trichoptera). Det Kongelige Danske Videnskabernes Selskab, Biologiske Skrifter 5:1-200.

Ross, H. H. 1956. The Evolution of the Mountain Caddisflies. University of Illinois Press, Urbana, Illinois, 213 pp.

Wells, A. 1990. The hydroptilid tribe Stactobiini (Trichoptera: Hydroptilidae) in New Guinea. Invertebrate Taxonomy 3:817-849.

Wiggins, G. B. 1996. Larvae of the North American Caddisfly Genera, 2nd edition. University of Toronto Press, Toronto, $457 \mathrm{pp}$.

Received 20 July 2001; accepted 6 March 2002. 